\title{
Os sentidos e destinos do cuidar na preparação dos cuidadores de idosos
}

\author{
The meanings and destinies of caregiving in the preparation \\ of caregivers for the old-aged
}

\author{
Virgínia Lúcia Reis M affioletti ${ }^{1}$ \\ Cristina Maria Douat Loyola ${ }^{2}$ \\ Fortunée Nigri ${ }^{1}$
}

${ }^{1}$ Centro para Pessoas com

Alzheimer e Outros

Transtornos M entais na

Velhice, IPUB/UFRJ. Av.

Wenceslau Brás, 71

- Fundos. 22290-140 Rio

deJaneiro RJ.

vmaffioletti@hotmail.com

${ }^{2}$ Escola de Enfermagem

Anna Nery,

UFRJ.
Abstract In this paper we present sometheoretical presuppositions with respect to the qualification of old-age caregivers proposed by two courses of the city of Rio de Janeiro. We adopted a qualitativemethodology, using asinstruments for data collection direct observation, tape recording of the ministered classes and interviews with the course managers. Documental sources were the course programs, texts and lists of source materials. The data were ordered in descriptive categories that werecompared with theliterature. Weemphasize: the difference between invisible care, visible care and technical care; the idea of care as a natural valuewith no need for technical qualification and the concepts of social care and health care. We believe that on giving emphasis to social care (moving away from the figure of disease) or to health care (whose core subject is disease) without paying attention to the importance of technical care, we are not considering the complexity of the subjective and physical aspects of the concrete existence of the old-aged sick individual.

Key words Elderly, Caregiver, Psychosocial re habilitation
Resumo Neste trabalho apresentamos alguns pressupostos teóricos que informam a preparação de cuidadores de idosos, proposta por dois cursos realizados na cidade do Rio de Janeiro. Utilizamosuma metodologia qualitativa adotando como instrumentos de col eta de dadosa observação participante e gravação das aulas, entrevistas com os coordenadorese, como fontes documentais, os programas, apostilas e referências bibliográficas. Os dados, ordenados em categorias descritivas, foram analisados à luz da literatura. Concluímos com uma reflexão acerca dos pressupostos que têm referenciado a preparação dos cuidadores de idosos e suas conseqüências para o cuidar, inclusiveo debate entre estes e a enfermagem. Destacamos: a oposição entre cuidados invisíveis, cuidados visíveis e cuidados técnicos; a naturalização do cuidar como um valor em detrimento de um aprendizado técnico; e as concepções de cuidado social e cuidado com a saúde. Consideramos que tanto a ênfase no cuidado social, ao afastar a figura mé dica da doença, quanto a ênfaseno cuidado à saúde, quetem a doença como motereflexivo, ao desconsiderarem a importância do cuidado técnico, podem, com isso, não levar em consideração a complexidade dos aspectos subjetivos e físicos ligados à existência concreta do enfermo idoso.

Palavras-chave Idosos, Cuidador, Reabilitação psicossocial 


\section{Introdução}

Esteartigo éparte do estudo quese propôs a identificar o perfil dos cursos que objetivam preparar cuidadores para assistir pessoas idosas com variados graus de dependência e comprometimento da autonomia.

A intenção da proposta de preparação de cuidadores de idosos se inscreve no movimento social que busca criar uma nova mentalidade capaz de acolher a velhice, construindo para isso uma nova subjetividade na qual ela compareça de uma forma mais construtiva. A construção dessa nova mentalidade tem proposto que o acoIhimento da velhice dependente seja feito, na medida do possível, em nível familiar e no domicílio ${ }^{1,2}$. Desta forma, ela possibilita para a veIhice, para a doença e para a morte uma ressignificação e propõe que Ihes seja permitido transitar, novamente, no espaço doméstico com naturalidade e propriedade. 0 desafio desta proposta surge na medida em que esse acolhimento demanda uma mudança de paradigma, de forma que a velhice, a doença, a dependência e a morte deixem de ser percebidas como inimigas da vida e sejam aceitas como partes da mesma.

Contudo, a literatura não se cansa de revelar a carência da rede assistencial para 0 atendimento dessa população e apoio às famílias que, por desejo ou obrigação, sepropõem a cuidar dosseus velhos. Apesar do esforço de a gerontologia dar visibilidade à velhice por meio da referência à cidadania, visando, fundamental mente, à reformulação da redeassi stencial eadministrativa, deforma a incluir uma atenção especializada e diferenciada ao velho - reconhecendo-o como sujeito social e sujeito de direitos -, o que se assiste é bem contrário àquele esforço. Indivíduos que, pelas contingências, vivem uma velhice acompanhada de doenças que Ihes impõem uma condição de maior dependência continuam condenados à invisibilidade 3 .

Na mesma situação encontra-se o trabalho do cuidador que compartilha da pouca visibilidade diante da parca estrutura assistencial, da desvalorização do seu trabalho assumido como uma atribuição natural das mulheres tanto em nível público, quanto em nível familiar, e pela rejeição social que condena à solidão todos aqueles que ousam semanter próximos da dor edo sofrimento. Essa invisibilidade do papel do cuidador, ao mesmo tempo em que compromete a leitura do cuidar, naturalizando-o e desvalorizando-0, não Ihe oferece oportunidades de treinamento e apoio. 0 alto custo emocional efísico desta fun- ção tem sido freqüentemente citado pelos estudiosos que, dentre outras coisas, o associam ao despreparo dos cuidadores informais e formais que assumem a responsabilidade do cuidar ${ }^{2,4-6}$.

Entretanto, o surgimento do cuidador formal como uma nova categoria profissional, sob a exigência dessa nova mentalidade deassistência para os velhos, não pode ser entendida como uma resultante exclusiva das pressões do campo gerontológico. Ela se inscreve no campo do cuidar apesar das resistências que tem encontrado -, porque há compatibilidade entre a nova mentalidade e a estrutura social, numa lógica interna que Ihe dá sustentação: há uma pressão social e econômica que obriga os membros da família a se inserirem no mercado de trabalho; há uma demanda e uma oferta que se inscrevem na fragmentação dos saberes, da prestação de serviços desregulamentada, da carência de uma rede de serviços públicos especializada; e há a exigência de minimizar custos.

Neste contexto, os cursos de preparação de cuidadores, agenciados por entidades não-governamentais, se inserem na qualidade de facilitadores dessa metamorfose do cuidar como atividade doméstica ligada à reprodução da vida em atividaderemunerada e pública, movida por uma exigência demaior qualificação. 0 objetivo épromover uma qualificação profissional que instrumentalize os indivíduos para ingressarem no mercado de trabalho no papel de cuidadores, constituindo um novo recorte profissional que leve em conta a especificidade da velhice, considerando as ressonâncias do envelhecimento orgânico, das patologias que podem acompanhálo e das respostas sociais que determinam atitudes de rejeição ou acolhimento. Entre o interesse das famílias de oferecer uma assistência que não onere mais ainda seus custos e 0 interesse dos profissionais de garantir para si um lugar no mercado de trabalho, cabe aos cursos a responsabilidade de fazer convergir esses interesses numa assistência de qualidade.

\section{M étodo}

Na pesquisa foi utilizada uma metodologia qualitativa, já que o fenômeno em estudo era complexo, de natureza social e cultural. Tomamos como fontes da pesquisa dois cursos de preparação para cuidadores de idosos na cidade do Rio de Janeiro, pelos quais nos foi dado o consentimento livre e esclarecido, assinado pelos coordenadores dos cursos e suas chefias diretas. A esco- 
Iha dos cursos se deu por estarem entre os mais antigos na cidade do Rio de Janeiro (atuantes há nove anos em 2002); por manterem uma regularidade na oferta do curso - uma média de três turmas por ano, cada uma com uma carga de 60 e36 horas/aula, respectivamente; pelo contingente de profissionais que já estavam atuando no mercado, respaldados em seus ensinamentos; e por contarem com uma equipe multidisciplinar de professores?.

Como métodos de coleta de dados, nós adotamos os seguintes procedimentos:

- os programas, currículos, apostilas e referências bibliográficas na qualidade de fontes documentais;

- a gravação das aulas ministradas na última turma de cada curso, no ano de 2002;

- um diário de campo, no qual foram registradas as observações feitas em todos os contatos com os coordenadores dos cursos e durante as aulas assistidas, pontuando eventuais contradições entre o discurso e as atitudes assumidas na prática perante os alunos e a própria pesquisa, considerando as práticas didáticas e metodológicas, os objetivos e as representações sobre 0 cuidar e a velhice;

- uma entrevista semi-estruturada, realizada com os coordenadores dos cursos (um total de cinco entrevistas), a qual foi elaborada contando com os subsídios obtidos na análise do material coletado, visando aumentar o conhecimento sobre o objeto.

Na análise, os dadosforam ordenados em unidades básicas descritivas quese relacionavam entre si de forma a ressaltar padrões, semel hanças e diferenças, repetições, temas e conceitos.

$\mathrm{Na}$ interpretação, buscamos atribuir significados à análise, explicando os padrões encontrados e identificando relacionamentos entre as dimensões descritivas, sob a luz de um exame detalhado da literatura que traz reflexões acerca dos aspectos encontrados e suas conseqüências para o cuidar.

\section{Resultados}

Com este estudo, nos foi possível colocar em evidência al gumas temáticas presentes na preparação desses profissionais. Dentre elas, a consideração do cuidar como sendo diferente da técnica, através da qual eles buscam demarcar o lugar ético dos cuidadores de idosos e estabelecem um debate com a enfermagem, justificando sua continuidade e legitimando essa nova profissão. Em seu esforço, os cursos desdobram o cuidar primeiramente em três dimensões: os cuidados visíveis, os cuidados invisíveis e a técnica.

O cuidar é concebido pelos cursos como um potencial do humano, referido a uma atitude diante da vida, diante do outro, do social, do ambiente. Uma atitude que depende de o indivíduo reconhecer a condição humana do outro. Uma dimensão de cuidado invisível informada pelas experiências pessoais de cada um e determinante da possibilidade de oferecer um acolhimento humanizado e respeitoso, reconhecendo a singularidade do paciente.

Como complemento dos cuidados invisíveis, os cursos orientam sobre os cuidados visíveis, tais como o auxílio nas atividades de vida diária, os quais são percebidos como fruto de um aprendizado cotidiano possível a qual quer um que esteja envolvido com a manutenção e reprodução da vida - o que éculturalmente delegado às mulhe res - etêm uma importância secundária. Deacordo com tal concepção, esses cuidados visíveis dispensam um aprendizado acadêmico e podem ser realizados de forma mecânica e descuidada, mesmo por aquele que tem um nível socioeducacional elevado e uma formação técnica, quando na ausência dessa atitude de cuidado invisível.

A técnica é entendida como uma forma mais ilustrada de realizar esses procedimentos, promovendo uma economia de esforços, porém, não garantindo, por si só, um cuidado de qualidade, entendido como uma implicação no destino do outro que leve em conta suas demandas e desejos.

Desta forma, os dois cursos tendem a relativizar a importância do cuidado técnico, como sendo dispensável para o cuidador, já que a função que lhe cabe está mais relacionada com um acompanhamento do velho. Os procedimentos de cuidado que realiza devem se limitar a reproduzir estratégias de autocuidado, comuns nas atividades de vida diária de todos, transpostas para o cuidado a um outro - banho, alimentação etc. Para eles, essas estratégias de cuidados são aprendidas naturalmente no processo de socialização feminina, sustentadas por uma capacidade de maternagem "natural" às mulheres. Em contraposição, os coordenadores dos cursos relacionam as denúncias de abandono, violência e maus-tratos a que eram submetidos os velhos internados nos asilos e clínicas geriátricas, à existência de uma equipe de profissionais tecnicamente qualificados, porém eticamente distorcidos. Sendo assim, o curso de preparação de cuidadores visa contribuir para a criação de uma rede de serviços al- 
ternativos e construir uma nova atitude da sociedade em relação ao cuidado oferecido aos veIhos.

Contudo, levando em consideração os dados observados na documentação analisada ( programas, textos, apostilas) e no conteúdo das aulas assistidas - principalmente aquelas que buscavam passar informações das áreas biomédicas - , identificamos, contraditoriamente, uma valorização da técnica e do conhecimento formal para a realização deum diagnóstico criterioso da condição do velho e para a construção do projeto de cuidados. Sendo assim, ressalta-se que a relativização da técnica recai fundamentalmente sobre os cuidados que correspondem à prática da enfermagem, o que nos leva a pensar que, dentre outras razões, essa foi a forma encontrada pelos cursos para enfrentar o debate estabelecido com a enfermagem, justificar sua continuidade e legitimar a profissão do cuidador.

Ao mesmo tempo, em meio a essa discussão, a noção de cidadania é assumida como um eixo norteador do cuidar pelos cursos, os quais propõem o cuidar como instrumento de inclusão social, tanto para o velho quanto para o cuidador. Para o vel ho, um novo lugar social; e, para o cuidador, a possibilidade de se inserir em um mercado de trabalho. Sendo o cuidar o instrumento da inclusão, os cursos estabelecem com a prática da enfermagem um outro debate que introduz uma segunda divisão do cuidar: a noção de cuidado social e a noção de cuidado com a saúde.

O cuidado social, que é colocado como referência central de uma atitude diante da vida, insere-se em um movimento mais amplo de reformulação social necessário para o acolhimento da velhice. Assim, ele abarca a dimensão clínica referida à saúde propriamente dita -, a dimensão política, social, cultural e jurídica. Com essa perspectiva, os cursos operam um deslocamento da figura da doença, da dependência, como um eixo reflexivo do cuidado, centrando-se no indivíduo e suas circunstâncias, tomando a velhice como uma questão social, tendo como inspiração as propostas da reabilitação psicossocial.

Paralelamente, continua o investimento na perspectiva do cuidado com a saúde, sustentando uma ênfase na figura da doença e da dependência como eixo reflexivo do cuidado, o qual se centra nos comprometimentos e nos manejos mais adequados para garantir bem-estar ao sujeito enfermo, considerando suas circunstâncias. 0 pressuposto assumido éo dequeéfundamental conhecer a doença e falar da fragilidade hu- mana, de sua condição trágica devida ao sofrimento e à consciência da inexorabilidade da morte, para que seja possível suportar a "velhice" e tratá-la com dignidade. Desta forma, eles acreditam que ajudam a romper com o tratamento medíocre que costuma ser dado ao velho e, em especial, ao velho doente.

\section{Discussão}

A reflexão sobre as práticas do cuidar traça uma historiografia que o considera próprio à natureza das mulheres, como se fosse al go determinado pelo orgânico. Uma concepção que encontra registro, desde os relatos de sociedades consideradas primitivas, até os dias de hoje. Em todas as épocas e, na maioria das sociedades, cabe às muIheres cuidar dos doentes, das ações relacionadas à facilitação do crescimento e desenvolvimento das crianças, dos velhos, assim como viabilizar as condições para que os homens mantenham suas forças para o trabalho ${ }^{8}$.

D onzelot ${ }^{9}$ comenta que, até meados do século 18, a medicina não tinha interesse nas mulhe res e crianças. As práticas de cuidado exercidas no âmbito doméstico não mereciam atenção e eram exercidas pelas comadres, pelas domésticas e pelas nutrizes que compartilhavam seu saber $e$ sua prática. A medicina doméstica surge colocando-se a serviço dos ideais higienistas e converte as práticas do cuidar, exercidas no âmbito privado das famílias, em uma nova estratégia de controle. As mulheres foram convocadas a assumir o status de guardiãs completas das crianças e dos doentes, exercendo a arte da enfermagem doméstica, tornando-se parceiras dos médicos. Essa promoção da mulher ao status de educadora e auxiliar médica Ihe conferiu um novo poder na esfera doméstica. Esse movimento se deu, obviamente, no seio das famílias abastadas.

Num certo momento da história do O cidente, o exercício dessa prática, em nível público, foi considerado perigoso, pecaminoso, pela Igreja, que tomou para si essa responsabilidade, regulada agora pelo poder religioso institucionalizado, mas ainda sob o domínio das mulheres - as irmãs de caridade. $\mathrm{Na}$ esfera doméstica, ela permanecia sendo uma responsabilidade das mulheres da casa. Até então, o cuidar era feito de maneira intuitiva, dispensando uma aprendizagem formal.

Naquela época, havia uma atitude complacente com a velhice, a doença e a morte, que Ihes permitia transitar no espaço doméstico com na- 
turalidade e propriedade. A partir da metade do século 19, como conseqüência do desenvolvimento das sociedades industriais, a dor, a doença, a morte e, conseqüentemente, a velhice, foram proibidas de transitar no espaço doméstico por um pacto de costumes e, nas palavras de Pitta ${ }^{10}$, aprisionadas e privatizadas no espaço hospitalar sob novos códigos e formas de relação.

Seguindo o desenrolar desse movimento, no final do século 19, um novo embatese inicia, agora entre uma concepção científica do cuidar e a religião. Florence Nightingale cria a enfermagem científica regida por um saber técnico e um controle moral. A enfermagem científica vem se desenvolvendo, desde então, fundamentada no desenvolvimento de técnicas orientadas pelo modelo da racionalidade científica, ou seja, pela noção de que as ciências naturais devem, pelo método experimental, procurar pelas leis dos fenômenos naturais, construindo a partir delas um modelo conceitual de forma a poder prevê-los, dominá-los e alterá-los quando necessário ${ }^{11}$.

Eticamente, as enfermeiras deveriam se inspirar nos valores morais das irmãs de caridade devoção, dedicação, obediência - , além de se subordinar ao saber médico e ao conhecimento científico. Seu comportamento deveria ser pautado pelo rigor moral, queincluía a contenção emocional e sexual. Até os dias de hoje, a técnica da enfermagem configura-se por meio de normas, rotinas, roteiros, manuais, padrões avaliativos e classificatórios, uma prática organizada como um instrumento disciplinador da conduta clínica da enfermagem, mas queacaba por ser exercidacom o mesmo sentido disciplinar com os pacientes ${ }^{12}$.

Observamos que a discussão apresentada pelos cursos, entre o cuidar intuitivo e afetivo que é, supostamente, natural às mulheres e o cuidar que deve ser instruído por um saber técnico/científico, perpassa a enfermagem desde a sua origem. Criticando a assistência prestada pelas muIheres enfermeiras de sua época, as quais não tinham uma formação específica e apresentavam, normalmente, distorções de caráter que comprometiam a imagem da profissão, Nightingale ${ }^{13}$ questionou a afirmação de que qual quer mulher pode vir a ser uma boa enfermeira e afirmou 0 contrário, que os princípios fundamentais, a essência da enfermagem, continuavam naquela época completamente desconhecidos. Em sua opinião, a arte da enfermagem, da forma como era praticada, pareciater sido criada especialmente para desfazer o que Deus determinou que a doença fosse, isto é, um processo restaurador.

No entanto, a crítica que se anuncia no dis- curso dos coordenadores dos cursos refere que a sofisticação dos procedimentos conquistada pela enfermagem não se revelou necessariamente em um aumento na qualidade da assistência prestada por esses profissionais. Eles acusam de haver uma contradição ética presente, já que o rigor moral prescrito pela formação e 0 acúmulo de conhecimentos não garantem uma atenção humanizada que leve em consideração o indivíduo e seu sofrimento, denotando um hiato entre a teoria e a prática, assim como não impede que distorções éticas e de caráter ocorram.

De certa forma, al guns autores associam esta contradição à identificação da assistência de enfermagem com a prática médica que, ao colocar a ênfase na doença, introduziu, no seio de uma prática que se descreve como "a ciência e a arte decuidar", uma contradição de princípios- o cuidar da pessoa versus o cuidar da doença. Silva ${ }^{12}$ observa que essa discussão informou e organizou a proposta do novo currículo da formação da enfermagem, o qual, mesmo se mantendo conectado ao modelo biomédico e ao enfoque técnico, introduziu uma abordagem diferenciada, em que a relação enfermeiro-paciente tornou-se objeto de cuidado. A autora, comentando essa nova perspectiva conciliatória entre o paradigma biomédico e o que ela chamou de "paradigma holístico", ressalta que para o cuidado técnico nos procedimentos de cuidados visíveis existem manuais que prescrevem intervenções, rotinas de procedimentos etc., e que o cuidado invisível não é normatizado em nenhum manual. Salienta, ainda, que o cuidado de enfermagem como um processo interativo deve ter um significado tanto para quem o realiza (enfermeiro ou técnicos) quanto para aquele que o recebe (paciente). 0 que se observa, contudo, é que, embora a enfermagem contemporânea tenha adotado um paradigma holístico, continua planejando sua assistência informada pelo paradigma biomédico. A autora afirma quecom esta perspectiva desloca-seo paciente de sua condição de pessoa, para configurar um segmento corporal enfermo. A referência para as ações éo problema físico identificado pela evidência de um sintoma ou a patologia a que está associado.

Camacho ${ }^{14}$, refletindo sobre o cuidado de enfermagem oferecido ao velho - especialmente 0 velho enfermo hospitalizado -, identificou uma prática contaminada por um imaginário cultural que comprometia a interação dos profissionais com o velho, e formulou uma crítica ao ensino da enfermagem na medida em que este [...] estabelece a importância do cuidado holístico, mas 
se esquece de um movimento muito maior que é a singularidade que o cuidado de enfermagem possui para uma determinada clientela, no caso [...] a idosa.

Este é um dos argumentos utilizados pelos cursos estudados sobre o lugar e a especificidade da preparação de cuidadores, isto é, a importância do ensino da gerontologia demarcando uma especificidade clínica. A partir destas idéias, podemos considerar fundamentais para o cuidado dois aspectos: a idéia de uma especificidade clínica da velhice e a noção de singularidade. A especificidade da velhice, por estar relacionada com as ressonâncias do envelhecimento biológico, dos lugares e discursos que definem o lugar do velho no social e na família, e suas conseqüências sobre a vida dos indivíduos envelhecidos como referência para uma assistência diferenciada. E a singularidade, queé particular e única para cada sujeito, pois está referida à sua história, como fundamento para um cuidado singularizado queleve em consideração a forma como cada um vive sua velhice e seu adoecer dentro do contexto em que está inserido.

No nosso estudo, observamos que, apesar do tom acusatório da crítica feita pelos cursos em relação à prática da enfermagem, o mesmo conflito se reproduz na preparação dos cuidadores de idosos oferecida por eles. Teoricamente, a ênfase é dada numa atenção integral (holística) ao indivíduo, levando em consideração a sua singularidade. No entanto, as orientações objetivas sobre os cuidados seguem, como já ressaltamos anteriormente, as prescrições de referenciais clínicos que também se orientam, implicitamente, pela lógica biomédica (nutrição, fisioterapia, fonoaudiologia), mas, neste caso, sem a exigência de que os cuidadores se apropriem de técnicas específicas.

De maneira geral, os cursos fundamentamseno seio de um pressuposto cartesiano quetem como ideal terapêutico a seguinte lógica gramatical: Eu sei por que você sofre e o que fazer com o seu sofrimento ${ }^{15}$. Mesmo o sofrimento psíquico encontra-se submetido a essa lógica, só que as intervenções são orientadas pela perspectiva da reabilitação psi cossocial. As demandas dos sujeitos que escapam, ou não se convertem a esse universo, são consideradas distorções inexoráveis de correntes da velhice, "coisas de velho", e se tornam alvos de interpretações impessoais.

Devemos lembrar que a noção de reabilitação surgiu na tradição médica, a qual, tendo na noção decidadania sua referência, organizou um campo de discussão pertinente. Sua origem está referida à reabilitação motora, ortopédica etc. Atualmente, a palavra de ordem que melhor representa esse paradigma tem si do "funcional idade". 0 comprometimento da funcionalidade social, psicológica, motora etc. é o indicador das condições de saúde/doença do indivíduo. Assim, cabe ao cuidador zelar e investir na funcionalidade do velho, de forma a mantêlo inserido na sociedade e na família.

O cuidar passa, então, a ser pensado como meio para a manutenção ou reinclusão social, tanto para o velho quanto para o cuidador, adotando a cidadania como um eixo norteador. A noção de cuidado social apresenta-se como uma forma de cuidado com a saúde, contrapondo-se aos mecanismos deexclusão e estigmatização. Os modelos de intervenção propostos assumem a velhice como uma questão social.

0 risco dessa perspectiva é que o cuidador, inadvertidamente, assuma uma atitude disciplinadora das condutas, sentimentos e desejos do velho. Podemos referir como exemplo as novas formas denomeação adotadas, tais como "jovens da terceira idade" e as novas formas de socialização oferecidas para os velhos: Universidade da Terceira Idade, clubes da nova idade etc. Devemos ressaltar, contudo, que não se trata de pôr em dúvida a validade dessas propostas, mas sublinhar que não se aplicam aos velhos enfermos cujas debilidades os impedem de circular com independência e autonomia nesses espaços. Ape sar da valorização da autonomia como indicador de "saúde", corre-se o risco de desrespeitar a possibilidade de o velho, mesmo que saudável, não se identificar com as novas imagens e atividades propostas e desejar para si outras formas de viver.

Ao mesmo tempo, clama-se pela construção de uma rede assistencial e de uma clínica diferenciada que contemple as demandas e especificidades desse crescente contingente populacional, sustentando uma ênfase na figura da doença, da dependência, como um segundo eixo reflexivo do cuidado. Cresce também a preocupação com o alto custo financeiro, emocional e físico que recaem sobre as famílias dos velhos adoecidos.

Neste caso, o risco reside numa associação da doença com a vel hice, fican do as intervenções restritas à questão dos sintomas e do evitar a morte. Com isso, destitui-se e desqualifica-se a fala dos sujeitos e seu direito de deliberar sobre os caminhos do seu tratamento e sobre a própria vida.

As duas concepções de cuidado se fazem presentes nos cursos, estabelecendo-se, entre elas, a 
diferença em termos da hierarquia. Convivem as perspectivas da remissão dos sintomas, que trabalha com a figura da doença como eixo que antecede 0 sujeito e suas circunstâncias, e a perspectiva do cuidado social que tenta deslocar o olhar dos sintomas para o sujeito, tomando a veIhice como uma questão social.

Apesar de representarem duas posições sobre o cuidar como mecanismo de tratamento e inclusão social, cada uma definindo para si um destino, podemos identificar que buscam alcançar um mesmo fim, qual seja, dar um outro lugar social para o velho, em especial para o velho em situação de dependência. A posição do cuidado social enfatiza a dimensão política e social, propondo a superação da clínica; e a posição do cuidado na saúde considera haver na condição da velhice uma especificidade que só a clínica é capaz de acolher de forma positiva.

Devemos estar atentos para as conseqüências dessas divisões, cuidado invisível e visível versus técnica, e cuidado social versus cuidado com a saúde. 0 desafio da gerontologia exigetanto a intervenção e o questionamento cultural e social mais amplos, quanto 0 enfrentamento da assistência qualificada aos velhos enfermos, que demanda um atendimento artesanal de cada situação, da particularidade de cada sujeito e seu contexto. Esta prática singular é a clínica, e o cuidador deve ser, antes de tudo, um agente de saúde. Tanto a ênfase no cuidado social - ao afastar a figura médica da doença - , quanto a ênfase no cuidado à saúde - que tem a doença como mote reflexivo - , ao desconsiderarem a importância do cuidado técnico, podem, com isso, não levar em consideração a complexidade dos aspectos subjetivos e físicos ligados à existência concreta do velho enfermo. Da mesma forma, relativizar a importância de qualificar tecnicamente o cuidador, para que possa reconhecer em suas intervenções uma dimensão clínica, pode ser uma forma de dizer que não se justifica o esforço pelo bem cuidar, já que a involução na vel hice e seu destino são inexoráveis.

Para al guns autores, problematizar essas questões insinua um fracionamento enganoso na assistência. Silva ${ }^{12}$ destaca que a rigor, na ação assistencial, os cuidados invisíveis, visíveis e técnicos são indissociáveis, na medida em que toda oferta de cuidado contempla 0 atendimento de questões sociais, culturais, religiosas e emocionais. Com essa perspectiva, a autora defendeque, na enfermagem, esse atendimento "holístico" acontece, mesmo quenão seja evidente nas ações de quem realiza o cuidado, e que este não seja reconhecido conscientemente como significativo - por quem o ministra ou por quem o recebe. Contudo, nos parecequeéexatamentenesseponto que reside a crítica feita à assistência de enfermagem, isto é, a pouca consciência deal guns profissionais de enfermagem em relação ao significado evalor dos cuidados invisíveis, para si epara o outro, pois eles implicam um afinamento da escuta para os apelos nem sempre claros ou precisos que nos sinalizam os tormentos vividos pelos sujeitos. Retomamos aqui a"ética da escuta", à qual se referiu Pitta ${ }^{16}$, aquela que revela uma disponibilidade interna, uma posição desejante do agente de cuidados de não se fazer indiferente.

O lugar ético apontado pela noção de cuidados invisíveis é a condição de possibilidade de uma assistência que pretende oferecer um cuidado singularizado. Ela, também, circunscreve os limites das intervenções invasivas e a possibilidade de reconhecimento e respeito à autonomia eàsingularidade. A atitudefundamental queestá em jogo éa bússola para que os atos eas palavras sejam orientados pela "ética da responsabilida$\mathrm{de}^{\prime 16}$, aquela que define os agentes de cuidados, isto é, profissionais que tomam para si a responsabilidade de cuidar.

\section{Considerações finais}

Fazer jus à formulação de "ciência e arte do cuidar", assim como a denominação de cuidador, exige que se leve em conta toda a tradição teórica e técnica de que se dispõe para traçar o plano de cuidados. Mas, ao mesmo tempo, é preciso levar em consideração todas as informações acessíveis sobre o paciente, que sua existência e seu destino sejam importantes para quem cuida dele. Dizendo de outra forma, a atitude de cuidado invisível indica que, como profissional, o cuidar foi escolhido como ofício, o que significa dizer que o sentido de sua própria existência está intimamente vinculado ao destino do outro.

Essa pareceser a razão fundamental pela qual os cursos se referem à atitude de cuidado invisível como definidora da posição ética de cuidador, relativizando a importância dos cuidados visíveis e da técnica. Em sua missão, os recursos exigidos do cuidador não são apenas para tratar, curar feridas, manter a vida elutar contra a morte, mas suportar junto o inexorável, o irreversível, um encontro capaz de guardar os sentidos da existência do sujeito, sendo esta uma dimensão de cuidado invisível. 
M as há um outro risco que pode advir dessa abordagem "holística" e sua ênfase na cidadania, pois ela propõe, de forma semelhante à proposta da reabilitação psicossocial, uma prática em que o cuidado social, o cuidado à saúdee a técnica se encontrem indissociáveis. 0 que implica assumir, para além do paciente, a família ea comunidade como lócus de intervenção. Um modelo deassistência que tende a medicalizar enormalizar o social, submetendo todos os indivíduos, inclusive os da comunidade - vizinhos, líderes comunitários e agentes religiosos -, às orientações dos especialistas em vel hice.

M ais uma vez é preciso repensar a concepção do que é velhice, do que é cuidar na velhice e os conceitos que orientam a preparação de cuidadores de idosos ou a formação de outros profissionais da saúde. Ao propor uma intervenção quecuide do velho eo mantenha na comunidade e na família, assumindo isso como um recurso terapêutico, o investimento devese destinar a fazer da rede social de suporte um instrumento de aceitação da diferença e não de normalização do social. Esta é a fronteira entre o mandato terapêutico e o mandato social de exclusão ${ }^{17}$.

Devemos lembrar quenão há como ter certeza das conseqüências dos nossos atos, pois seus efeitos têm ressonâncias que escapam à nossa observação imediata.

\section{Colaboradores}

VLR M affioletti participou de todas as etapas da realização do artigo. M CD Loyola participou no delineamento do artigo, da discussão teórica e metodológica. F Nigri participou do levantamento bibliográfico, bem como da discussão. Todos os autores participaram da elaboração final do artigo.

11. M iranda CML. O risco e o bordado: um estudo sobre formação de identidade profissional. Rio de Janeiro: Escola de Enfermagem Anna Nery/UFRJ; 1996.

12. Silva TJES. 0 enfermeiro e a assistência: a necessidade não física do cliente: o significado do fazer [tese]. Rio de Janeiro: Escola de Enfermagem Anna Nery/UFRJ; 1998.

13. Nightingale $F$. Notas sobre enfermagem: 0 que é e 0 que não é. São Paulo: Cortez; 1989.

14. Camacho ACLF. O cuidado de enfermagem ao cliente idoso hospitalizado: um estudo exploratório das representações dos profissionais de enfermagem [ dissertação]. Rio de Janeiro: Escola de Enfermagem Anna Nery/UFRJ; 2001.

15. M otta JM. Instituição, psicanálise e enfermagem em saúde mental: boas novas? Cadernos IPUB 2000; 19: 11-14. p.13.

16. Pitta AM F. Ética e assistência em psiquiatria. In: Figueiredo AC, Silva Filho JF, organizadores. Ética e saúde mental. $2^{a}$ ed. Rio de Janeiro: Topbooks; 2001. p. $103-10$.

17. Tenório F. A psicanálise e a clínica da reforma psiquiátrica. Rio de Janeiro: Rios Ambiciosos, 2001.

Artigo apresentado em 5/08/2005

Aprovado em 16/01/2006

Versão final apresentada em 17/03/2006 